\title{
Follicular and Hormonal Dynamics during the Estrous Cycle in Goats
}

\author{
Mohamed S. MEDAN ${ }^{1,2)}$, Gen WATANABE ${ }^{1,3)}$, Kazuaki SASAKI ${ }^{4}$, \\ Nigel P. GROOME ${ }^{5)}$, Sayed SHARAWY') and Kazuyoshi TAYA ${ }^{1,3)}$
}

\author{
1) Laboratory of Veterinary Physiology, Department of Veterinary Medicine, Faculty of \\ Agriculture, Tokyo University of Agriculture and Technology, Tokyo 183-8509, Japan, \\ ${ }^{2)}$ Department of Theriogenology, Faculty of Veterinary Medicine, Suez Canal University, \\ Ismailia, Egypt, ${ }^{3)}$ Department of Basic Veterinary Science, The United Graduate School of \\ Veterinary Sciences, Gifu University, Gifu 501-1193, ${ }^{4}$ Hitachi, Ltd., Central Research \\ Laboratory, Tokyo 185-8601, Japan, ${ }^{5)}$ School of Biological and Molecular Sciences, Oxford \\ Brookes University, Headington, Oxford OX3 OBP, United Kingdom
}

\begin{abstract}
Transrectal ultrasonography of ovaries was performed daily in 6 goats for 3 consecutive estrous cycles. Blood samples collected daily were measured for concentrations of FSH, inhibin A, and estradiol-17 $\beta$. Follicular and hormonal data were analyzed for associations between the follicular waves and hormonal concentrations. During the interovulatory intervals, follicular growth and regression occurred in a wave like pattern (2-5 waves), and the predominant patterns were three and four follicular waves. In addition, there was no significant difference among the diameters of dominant follicles during the growth phase of the follicular waves. The number of $3 \mathrm{~mm}$ follicles peaked on days 0,7 , and 11 in interovulatory intervals that had three follicular waves and on days -1 , 5,11 , and 15 in those that had four follicular waves. Plasma concentrations of FSH increased around the day of follicular wave emergence and declined with the growth of follicles. Circulating FSH increased again concomitant with regression of dominant follicles in the anovulatory wave, whereas FSH levels remained low in the ovulatory wave. Inhibin A was negatively correlated with FSH, while it was positively correlated with estradiol-17 $\beta$, suggesting that inhibin A is a product of healthy growing follicles and that it contributes to the suppression of FSH secretion. In conclusion, the growth of ovarian follicles in goats exhibits a wave-like pattern, and follicular dominance is less apparent in goats. Moreover, inhibin A may be a key hormone for regulation of the follicular wave through suppression of FSH secretion in goats.
\end{abstract}

Key words: Follicular dynamics, FSH, Goats, Inhibin, Ultrasound

(J. Reprod. Dev. 51: 455-463, 2005)

$\mathbf{T}$ date reports of caprine follicular waves and their associations with hormones during estrous cycle are limited. The development of ultrasonic probes that can be used intrarectally to visualize ovaries has opened new possibilities for examining the dynamics of follicular growth and

Accepted for publication: April 14, 2005

Correspondence: K. Taya (e-mail: taya@cc.tuat.ac.jp) regression [1] and has provided means for repeated, direct, non-invasive monitoring of ovarian activity [2] and pregnancy diagnosis [3, 4]. Previous ultrasound studies in goats indicated that ovarian follicles reaching ovulatory size throughout the estrous cycle exhibited a wave-like pattern [5-7]. The temporal relationships between follicular dynamics and hormonal profiles have 
been well clarified throughout the bovine and ovine estrous cycles. There is a temporal relationship between elevations in the mean daily serum concentrations of FSH and the emergence of successive follicular waves in cows $[8,9]$ and ewes $[10,11]$. Moreover, the role of inhibin in regulating the production and secretion of FSH has been documented in sheep [12,13], cattle [14-16], and mares [17, 18].

In the present study, we investigated follicular dynamics and the accompanying hormonal profiles during the goat estrous cycle. Also, we investigated the relationships among plasma concentrations of FSH, inhibin A, and estradiol$17 \beta$.

\section{Materials and Methods}

\section{Animals and experimental procedures}

Six adult, clinically healthy, Shiba goats that were 3 to 5 years old were used in the present study for 3 consecutive estrous cycles. The animals were housed in a sheltered outdoor paddock and fed hay cubes (700 g/head/day). Clean water, and mineralized salt licks were available ad libitum. Estrous cycles were synchronized with 2 injections of $125 \mu \mathrm{g}$ of a synthetic analogue of prostaglandin $\mathrm{F}_{2 \alpha}\left(\mathrm{PGF}_{2 \alpha}\right)$ (Estrumate, Schering-Plough Animal Health, New Jersey, USA) 11 days apart. Estrous behaviour was checked every $6 \mathrm{~h}$ with an aproned mature buck. Blood samples were collected daily during estrous cycles into heparinized vacutainer tubes (Terumo Venoject II, Tokyo, Japan) and centrifuged at $1200 \mathrm{~g}$ for $15 \mathrm{~min}$. Plasma was separated and stored at $-20 \mathrm{C}$ until assayed for hormones.

Each animal underwent transrectal ovarian ultrasonography using a B-mode scanner (ECHOPAL ultrasound scanner, Hitachi Medical Corporation, Tokyo, Japan) equipped with a 7.5 $\mathrm{MHz}$ transducer, as described previously [6]. Ultrasonic examinations were carried out daily and every $12 \mathrm{~h}$ around ovulation. All follicles $\geq 3 \mathrm{~mm}$ in diameter were recorded and their diameters were measured. Also, the diameter, position, and characteristics of the corpus luteum (CL) were noted. After freezing the image on the screen, the maximum internal diameter of each follicle was measured using the built-in electronic caliper. Each day, ovarian diagrams depicting the relative location of follicles and CL were made to determine patterns of growth and regression of individual follicles and CL.

\section{Follicle data analysis}

The total number of follicles $\geq 3 \mathrm{~mm}$ in diameter was assessed daily. The term wave was defined as one or more antral follicles growing from 3 to $\geq 5$ $\mathrm{mm}$ in diameter before regression $[6,10,19]$. The day of emergence of follicles was identified as the day on which the follicle was $3 \mathrm{~mm}$ in diameter. Individual follicles emerging within a maximum of $48 \mathrm{~h}$ were regarded as a single follicular wave. The following characteristics of follicular waves were determined for each animal: (1) the number of follicular waves; (2) the day of wave emergence; (3) the number of follicles growing to $\geq 5 \mathrm{~mm}$ in diameter per wave; (4) the maximum diameter attained by the largest follicle of the wave; (5) the number of days between the emergence of sequential follicular waves (interwave intervals). To determine follicular dynamics during anovulatory and ovulatory follicular waves, the data were normalized to the time of follicular wave emergence. The three largest follicles were tracked retrospectively depending on follicular diameters and were identified as F1 (largest), F2, and F3. The day of ovulation was identified as the first day on which a large follicle disappeared or collapsed [19] and was followed by the development of a CL at that site in the ovary. All procedures were carried out in accordance with the guidelines for the care and use of laboratory animals established by the Tokyo University of Agriculture and Technology.

\section{Hormone analysis}

Plasma concentrations of FSH were measured by radioimmunoassay (RIA), as described by Araki et al. [20], using anti-ovine FSH, NIDDK-FSH-I-1 for radioiodination, and NIDDK-oFSH-RP-1 as a reference standard. The intra and interassay coefficients of variation were $9.8 \%$ and $12.6 \%$, respectively. Plasma concentrations of estradiol$17 \beta$ were determined by a double antibody RIA system using ${ }^{125} \mathrm{I}$-labeled radioligands, as described previously [21]. Antisera against estradiol-17 $\beta$ (GDN 244) were kindly provided by Dr. G. D. Niswender (Animal Production and Biotechnology, Colorado State University, Fort Collins, CO, USA). The intra and interassay coefficients of variation were $5.7 \%$ and $7.4 \%$, respectively. Inhibin A was 
measured by ELISA as described for use in human plasma [22] and modified for use in sheep plasma [23].

\section{Statistical analysis}

Mean values $( \pm$ SEM) were calculated and analysed using 2-way ANOVA. Duncan's multiple-range test was used for detection of significant differences using the SAS computer package [24]. The follicles were combined for the 2 ovaries and the analysis of data began on day -2 rather than on day 0 (day of ovulation). The hypothesis that waves of follicles emerged at periodic intervals was tested by analysis of variance for sequential data to evaluate day effects averaged over 18 interovulatory intervals. A significant $(P<0.05)$ day effect was followed by Duncan's multiple-range test to detect significant nadirs and peaks. The association between emergence of follicular waves and the occurrence of identified FSH peaks was studied by paired t-test to compare the number of waves with the number of peaks per interovulatory interval and the interwave and interpeak intervals. In addition, Wilks' Lambda correlation was made between the number of follicular waves and the number of FSH peaks and between the interwave and interpeak intervals. Furthermore, Wilks' Lambda correlations were made among $\mathrm{FSH}$, inhibin $\mathrm{A}$, and estradiol-17 $\beta$.

\section{Results}

\section{Follicular dynamics}

Ultrasonographic images of ovarian structures are shown in Fig. 1. The follicles were detected as echo-free black circles while the corpora lutea were detected as a gray echogenic structure. The characteristics of follicular waves are shown in Table 1, and representative patterns of growth and regression of individual follicles are shown in Fig. 2. In all animals, the last follicular wave of the interovulatory interval $(21.3 \pm 0.4$ days; $n=18)$ contained ovulatory follicle(s) and the mean ovulation rate was $1.8 \pm 0.2$. The maximum diameters of the ovulatory follicles were significantly $(P<0.01)$ larger than the maximum diameter of the largest follicles of the other waves. In addition, there was no significant difference among the diameters of the three largest follicles of
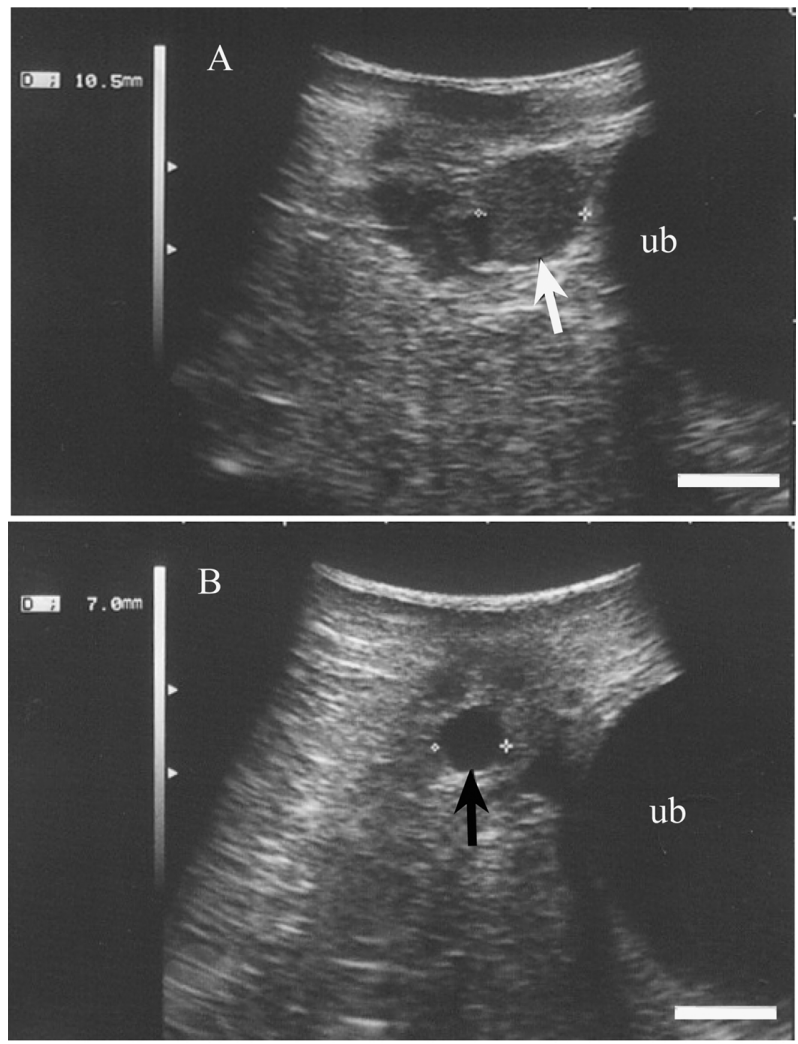

Fig. 1. Ultrasound images of goats' ovaries produced using a rigid, transrectal $7.5 \mathrm{MHz}$ transducer. (A) An ovary containing a corpus luteum of $10.5 \mathrm{~mm}$ in diameter (white arrow). (B) An ovary containing an antral follicle of $7.0 \mathrm{~mm}$ in diameter (black arrow). The scale bars represent $10 \mathrm{~mm}$ and $\mathrm{ub}$ indicates the urinary bladder.

the follicular waves during the growth phase, and multiple follicles grew simultaneously and ovulated during the ovulatory wave. The number of $4 \mathrm{~mm}$ follicles emerging per day that subsequently grew to $\geq 5 \mathrm{~mm}$ in diameter is shown in Fig. 3. The number of $3 \mathrm{~mm}$ follicles peaked on days 2 and 11; 0,7 , and $11 ;-1,5,11$, and 15; and -1 , $2,7,11$, and 15 in interovulatory intervals which had two, three, four, and five follicular waves, respectively.

Follicular dynamics and hormonal profile during the first (anovulatory) and final (ovulatory) follicular waves of the estrous cycle

Follicular dynamics during anovulatory and ovulatory follicular waves are depicted in Fig. 4 A and $B$. There was no significant difference between the largest three follicles during the growth phase (from follicle emergence to day 4). Plasma FSH 
Table 1. Characteristics of follicular waves in 18 interovulatory intervals

\begin{tabular}{|c|c|c|c|c|c|c|c|c|c|c|}
\hline \multirow{3}{*}{$\begin{array}{l}\text { Interovulatory } \\
\text { interval with }\end{array}$} & \multicolumn{8}{|c|}{ Anovulatory waves } & \multicolumn{2}{|c|}{ Ovulatory wave } \\
\hline & \multicolumn{2}{|c|}{ Wave 1} & \multicolumn{2}{|c|}{ Wave 2} & \multicolumn{2}{|c|}{ Wave 3} & \multicolumn{2}{|c|}{ Wave 4} & \multirow[b]{2}{*}{$\mathrm{DE}$} & \multirow[b]{2}{*}{ MD } \\
\hline & $\mathrm{DE}^{1}$ & $\mathrm{MD}^{2}$ & $\mathrm{DE}$ & MD & $\mathrm{DE}$ & MD & $\mathrm{DE}$ & MD & & \\
\hline 2 waves $(n=2)$ & $2.0 \pm 0.5$ & $6.8 \pm 0.5^{\mathrm{b}}$ & - & - & - & - & - & - & $11.5 \pm 0.5$ & $8.2 \pm 0.3^{3}$ \\
\hline 3 waves $(n=5)$ & $0.3 \pm 0.3$ & $6.6 \pm 0.1^{b}$ & $6.5 \pm 0.2$ & $6.2 \pm 0.1^{\mathrm{b}}$ & - & - & - & - & $12.1 \pm 0.4$ & $8.0 \pm 0.1^{\circ}$ \\
\hline 4 waves $(n=9)$ & $-0.6 \pm 0.3$ & $6.7 \pm 0.1^{b}$ & $4.7 \pm 0.2$ & $6.2 \pm 0.2^{b}$ & $9.4 \pm 0.5$ & $6.3 \pm 0.1^{\mathrm{b}}$ & - & - & $13.4 \pm 0.5$ & $7.8 \pm 0.2^{2}$ \\
\hline 5 waves $(n=2)$ & $-1 \pm 0.5$ & $6.5 \pm 0.2^{\mathrm{b}}$ & $3.0 \pm 0.5$ & $6.0 \pm 0.2^{b}$ & $7.0 \pm 0.5$ & $6.1 \pm 0.2^{b}$ & $11.5 \pm 0.5$ & $6.2 \pm 0.3^{\mathrm{b}}$ & $15.5 \pm 0.5$ & $7.8 \pm 0.2^{2}$ \\
\hline
\end{tabular}

a,b Values with different superscripts are significantly different $(P<0.01)$.

${ }^{1}$ Day of emergence (day).

${ }^{2}$ Maximum diameter ( $\left.\mathrm{mm}\right)$.
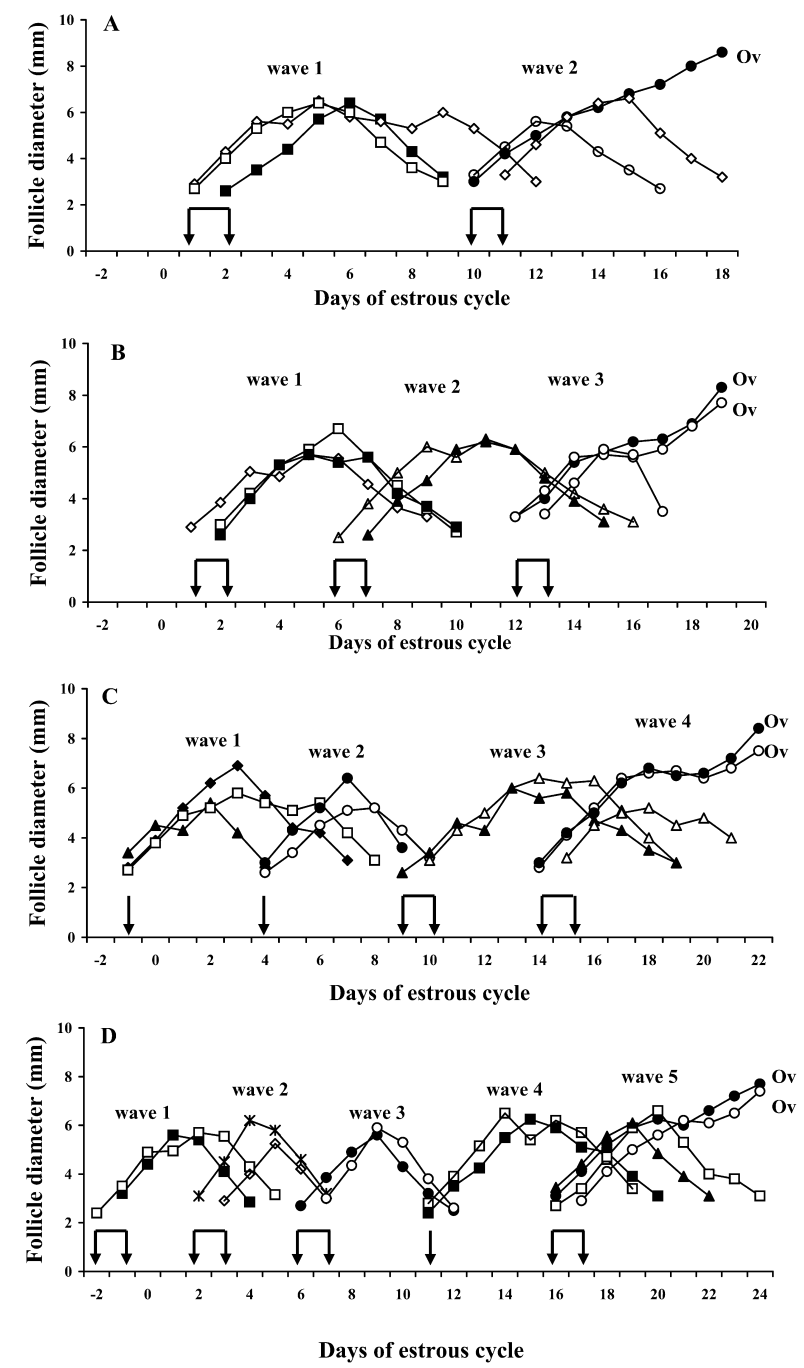

Fig. 2. Representative patterns of growth and regression of individual follicles during the estrous cycles in goats with two (A), three (B), four (C), and five (D) waves of follicular development. Arrows indicate the emergence of follicular waves, and different symbols indicate different follicles in each follicular wave $(\mathrm{Ov}$ = ovulation). concentrations were high around the day of follicular wave emergence for each follicular wave and decreased significantly $(P<0.05)$ to a nadir level on day 4 (Fig. 4 C,D). FSH concentrations increased again on day 7 , concomitant with regression of follicles in the anovulatory waves (Fig. 4 C), or remained at a lower level in the case of ovulatory waves (Fig. 4 D). On the other hand, plasma levels of inhibin A were low during follicular wave emergence and increased with the growth of follicles while FSH concentrations declined. Inhibin A levels declined with the regression of follicles in the anovulatory waves (Fig. 4 C) or remained at a higher level in the case of ovulatory waves (Fig. 4 D). Inhibin A and estradiol-17 $\beta$ concentrations increased significantly $(P<0.05)$ with the growth of follicles and declined concomitant with follicular regression in the anovulatory waves (Fig. 4 E) or remained at higher levels in the ovulatory waves (Fig. 4 F).

Associations between follicular waves and FSH peaks during interovulatory intervals are shown in Table 2. The number of emerging follicular waves and the number of identified FSH peaks per interovulatory interval did not differ. The duration of the interval between adjacent days of wave emergence (interwave intervals) was positively correlated with the duration of the interpeak interval for FSH fluctuations $(r=0.8 ; P<0.001)$. The length of the interval between emergences of waves did not differ significantly from the intervals between FSH peak values. The number of waves and the number of peaks were positively and significantly correlated $(r=0.8 ; P<0.001)$.

\section{Correlations among FSH, inhibin $A$, and estradiol- $17 \beta$}

Plasma levels of FSH, inhibin A, and estradiol- 

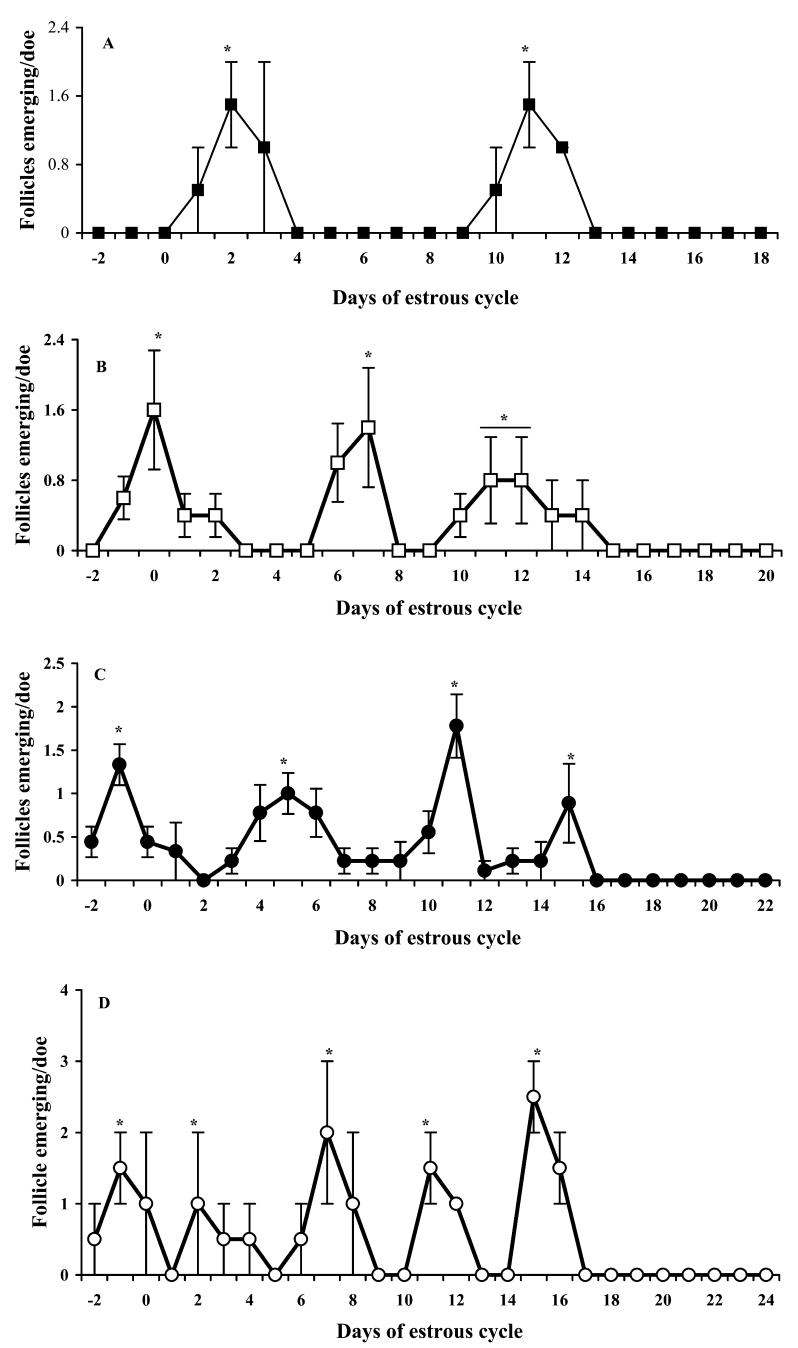

Fig. 3. Number of follicles emerging in goats with two $(A ; n=$ $2)$, three $(B ; n=5)$, four $(C ; n=9)$, or five $(D ; n=2)$ waves of follicular development. Values are means \pm SEM. Within a data set, stars indicate difference $(P<0.05)$ between peaks and encompassing nadirs.

$17 \beta$ were normalized to the day of follicular wave emergence (day 0). The correlations among FSH, inhibin $\mathrm{A}$, and estradiol-17 $\beta$ are shown in Fig. 5. A negative correlation was found between FSH and inhibin A $(r=-0.53 ; P<0.001)$ and between FSH and estradiol-17 $\beta(r=-0.41 ; P<0.001)$. However, there was a positive correlation between inhibin $\mathrm{A}$ and estradiol-17 $\beta(r=0.58 ; P<0.001)$.

\section{Discussion}

The results of the present study showed that the growth of antral follicles in goats occurs in a wavelike pattern and that the emergence of follicular waves was preceded by an increase in FSH secretions. In addition, growing follicles secreted inhibin and estradiol-17 $\beta$ which in turn suppressed FSH secretions. Previous studies in goats [5-7] showed that the growth and regression of large antral follicles is characterized by a wave-like pattern of follicular development. In this study, we found that the wave pattern ranged between 2 and 5 follicular waves. The day of emergence of waves for goats that have 4 waves was within the range reported by Ginther and Kot [5].

In previous studies using utltrasonography and blood sampling once daily, it was shown that large antral follicles (attaining $\geq 5 \mathrm{~mm}$ in diameter) grew in waves across the ewes estrous cycle, and that around the time of wave emergence (growth from 3 $\mathrm{mm}$ pool follicles) there was a transient elevation in plasma concentrations of FSH $[10,11]$. In the present study, we found a similar pattern of FSH secretion in which plasma FSH concentrations were high coincident with follicular wave emergence and then decreased after emergence. These results suggest that fluctuation of the circulating FSH levels is involved in the recruitment of follicles. The number of follicular waves and FSH peaks recorded in the present study did not differ, nor did the length of the intervals between waves versus FSH peaks. The positive correlation between the numbers of these two events within interovulatory intervals was high and significant, indicating a strong association between follicular wave emergence and FSH peaks. It is well established that the secretion of FSH during the estrous cycle is regulated by both inhibin and estradiol-17 $\beta$ in sheep and cattle $[13,25,26]$ and that injection of inhibin antiserum in goats $[27,28]$ increases FSH secretions and ovulation rate. In the present study, the inverse relationship between inhibin and FSH confirms the hypothesis that inhibin inhibits FSH secretion. In our previous report [7], we found an inverse relationship between FSH and inhibin A during the estrous cycle in goats that confirms the hypothesis that inhibin A contributes to the inhibition of FSH secretion.

Evidence concerning follicular dominance in small ruminants, such as sheep and goats, is still equivocal. While some authors have postulated the existence of follicular dominance especially during first and final follicular waves [29, 30], others are 

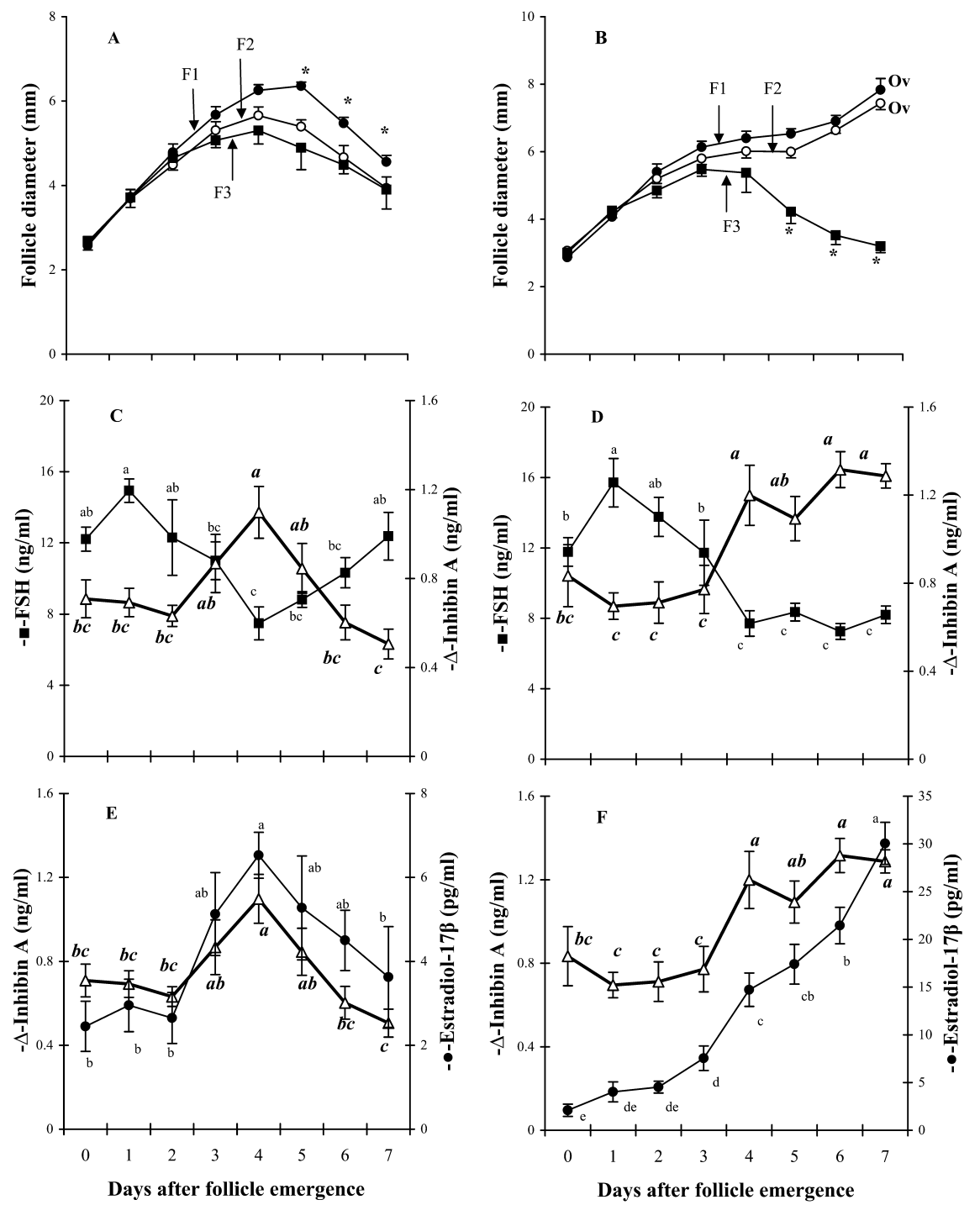

Fig. 4. Follicular dynamics and hormonal profiles during the anovulatory $(A, C, E)$ and ovulatory $(\mathrm{B}, \mathrm{D}, \mathrm{F})$ follicular waves of the goat estrous cycle. Panels A and B show the pattern of growth and regression of the three largest follicles (F1, F2, and F3). Panels $\mathrm{C}$ and D show the mean $( \pm$ SEM) plasma concentrations of FSH $(-\square-; n=18)$ and inhibin $A\left(-\triangle^{-} ; n=6\right)$, while panels $E$ and $F$ show the mean $( \pm$ SEM) plasma concentrations of inhibin $A\left(-\triangle^{-} ; \mathrm{n}=6\right)$ and estradiol-17 $\beta\left(-\mathbf{0}^{-} ; \mathrm{n}=18\right)$. Data are normalized to the day of follicular wave emergence (day 0$).{ }^{*}(P<0.05)$ significantly different from other follicles. Means without common characters are significantly $(P<0.05)$ different within the same data set. Ov=ovulatory follicles.

still dispute this [31, 32]. In ewes, follicular waves have been frequently found to emerge in the presence of growing ovulatory-sized follicles from a previous wave $[33,34]$ and large (presumably dominant) follicles do not inhibit equine chorionic gonadotropin (eCG)-induced growth of other follicles [31]. In the present study, there was no significant difference among the diameters of the three largest follicles of the follicular waves during the growth phase, and multiple follicles grew simultaneously and ovulated during the ovulatory wave. In addition, we found that several follicles grew coincidently during each follicular wave without affecting each other's growth. Therefore, we cannot confirm a clear powerful dominance in goats as in cattle. However, more than one follicle 
Table 2. Associations between follicular waves and FSH peaks

\begin{tabular}{lc}
\hline End point & Mean \pm SEM \\
\hline Interovulatory interval (IOI) & 18 \\
Number & $21.3 \pm 0.5$ \\
Length (days) & $3.6 \pm 0.2$ \\
Number of follicular waves/IOI $^{\mathrm{a}}$ & $3.9 \pm 0.2$ \\
${\text { Number of FSH peaks } / \mathrm{IOI}^{\mathrm{a}}}^{\mathrm{a}}$ & $5.6 \pm 0.3$ \\
Interwave interval $^{\mathrm{b}}$ (days) & $5.2 \pm 0.2$ \\
Interpeak interval $^{\mathrm{b}}$ (days) & \\
\hline
\end{tabular}

a No significant difference between the number of follicular waves and the number of FSH peaks. The number of follicular waves and the number of FSH peaks were positively correlated $(r=0.8 ; P<0.001)$.

${ }^{\mathrm{b}}$ No significant difference between the interwave intervals and interpeak intervals. The number of interwave intervals and the number of interpeak intervals were positively correlated $(r=0.8 ; P<0.001)$.

in goats may co-operate to exert a functional dominance on the growth of other follicles.

In conclusion, the growth of ovarian follicles in goats exhibits a wave-like pattern, and follicular dominance is less apparent in goats. Each follicular wave is preceded by an increase in FSH secretion. FSH is negatively correlated with inhibin A, suggesting that inhibin A contributes to the regulation of FSH secretions.

\section{Acknowledgments}

We are grateful to Dr. A.F. Parlow (National Institute of Diabetes and Digestive and Kidney Diseases, Beltsville, MD, U.S.A.) for providing RIA materials for ovine FSH and Dr. G. D. Niswender (Animal Reproduction and Biotechnology Laboratory, Colorado State University, Fort Collins, CO, U.S.A.) for providing antisera to estradiol- $17 \beta$ (GDN 244). This work was supported by a Grantin-Aid for scientific Research (The 21st Century Center of Excellence Program, E-1) from the Ministry of Education, Culture, Sports, Science and
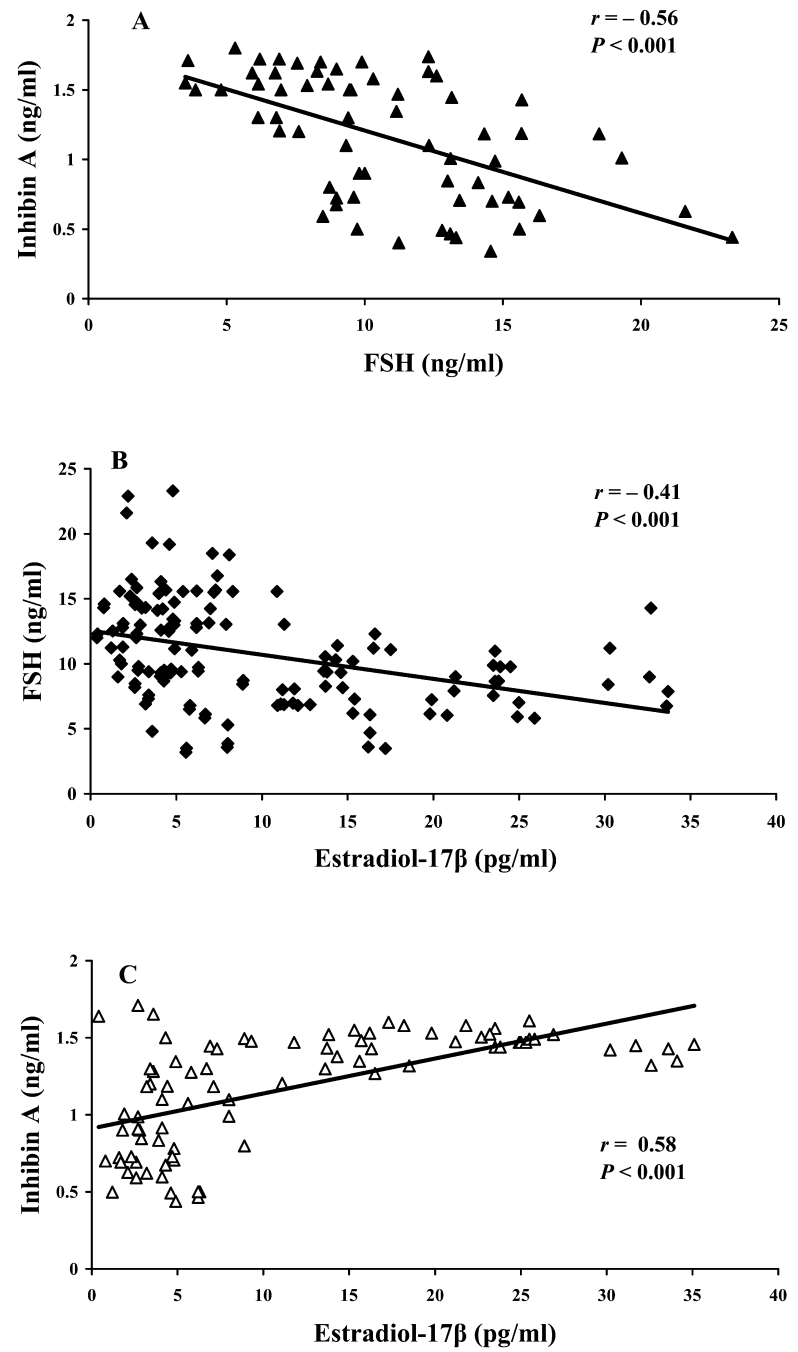

Fig. 5. Correlations between plasma concentrations of (A) FSH and inhibin A; (B) FSH and estradiol-17 $\beta$; and (C) inhibin $\mathrm{A}$ and estradiol-17 $\beta$ during the estrous cycle in goats.

Technology of Japan and a Grant-in-Aid for Scientific Research (No. 03338) from the Japan Society for the Promotion of Science.

\section{References}

1. Fortune JE, Sirois J, Turzillo AM, Lavoir M. Follicle selection in domestic ruminants. J Reprod Fertil 1991; 43 (Suppl): 187-198.

2. Griffin PG, Ginther OJ. Research applications of ultrasonic imaging in reproductive biology. J Anim
Sci 1992; 70: 953-972.

3. Martinez MF, Bosch P, Bosch RA. Determination of early pregnancy and embryonic growth in goats by transrectal ultrasound scanning. Theriogenology 1998; 49: 1555-1565. 
4. Medan M, Watanabe G, Absy G, Sasaki K, Sharawy S, Taya K. Early pregnancy diagnosis by means of ultrasonography as a method of improving reproductive efficiency in goats. J Reprod Dev 2004; 50: 391-397.

5. Ginther OJ, Kot K. Follicular dynamics during the ovulatory season in goats. Theriogenology 1994; 42: 987-1001.

6. de Castro T, Rubianes E, Menchaca A, Rivero A. Ovarian dynamics, serum estradiol and progesterone concentrations during the interovulatory interval in goats. Theriogenology 1999; 52: 399-411.

7. Medan MS, Watanabe G, Sasaki K, Sharawy S, Groome NP, Taya K. Ovarian dynamics and their associations with peripheral concentrations of gonadotropins, ovarian steroids and inhibin during the estrous cycle in goats. Biol Reprod 2003; 69: 57-63.

8. Kulick LJ, Kot K, Wiltbank MC, Ginther OJ. Follicular and hormonal dynamics during the first follicular wave in heifers. Theriogenology 1999; 52: 913-921.

9. Mihm M, Crowe MA, Knight PG, Austin EJ. Follicle wave growth in cattle. Reprod Domest Anim 2002; 37: 191-200.

10. Ginther OJ, Kot K, Wiltbank MC. Associations between emergence of follicular waves and fluctuations in FSH concentrations during the estrous cycle in ewes. Theriogenology 1995; 43: 689703.

11. Bartlewski PM, Beard AP, Cook SJ, Chandolia RK, Honaramooz A, Rawlings NC. Ovarian antral follicular dynamics and their relationships with endocrine variables in two breeds of sheep differing in prolificacy. J Reprod Fertil 1999; 115: 111-124.

12. Findlay JK, Clarke IJ, Robertson DM. Inhibin concentrations in ovarian and jugular venous plasma and the relationship of inhibin with folliclestimulating hormone and luteinizing hormone during the ovine estrous cycle. Endocrinol 1990; 126: 528-535.

13. Mann GE, McNeilly AS, Baird DT. Hormone production in vivo and in vitro from follicles at different stages of estrous cycle in sheep. J Endocrinol 1992; 132: 225-234.

14. Glencross RG, Bleach ECL, Wood SC, Knight PG. Active immunization of heifers against inhibin: effects on plasma concentrations of gonadotrophins, steroids and ovarian follicular dynamics during prostaglandin-synchronized cycles. J Reprod Fertil 1994; 100: 599-605.

15. Kaneko H, Noguchi J, Kikuchi K, Todoroki J, Hasegawa Y. Alterations in peripheral concentrations of inhibin A in cattle studied using a time-resolved immunofluorometric assay: relationship with estradiol and follicle-stimulating hormone in various reproductive conditions. Biol
Reprod 2002; 67: 38-45.

16. Kaneko H, Kishi H, Watanabe G, Taya K, Sasamoto S, Hasegawa Y. Changes in plasma concentrations of immunoreactive inhibin, estradiol and FSH associated with follicular waves during the estrus cycle of the cow. J Reprod Dev 1995; 41: 311320.

17. Nambo $\mathbf{Y}$, Kaneko $H$, Nagat $S$, Oikawa $M$, Yoshihara T, Nagamine N, Watanabe G, Taya K. Effect of passive immunization against inhibin on FSH secretion, folliculogenesis and ovulation rate during the follicular phase of estrous cycle in mares. Theriogenology 1998; 50: 545-557.

18. Medan MS, Nambo $\mathbf{Y}$, Nagamine $\mathbf{N}$, Shinbo $\mathbf{H}$, Watanabe G, Groome N, Taya K. Plasma concentrations of ir-inhibin, inhibin A, inhibin proalphaC, FSH, and estradiol-17beta during estrous cycle in mares and their relationship with follicular growth. Endocrine 2004; 25: 7-14.

19. Bartlewski PM, Beard AP, Rawlings NC. An ultrasound-aided study of temporal relationships between the patterns of LH/FSH secretion, development of ovulatory-sized antral follicles and formation of corporal lutea in ewes. Theriogenology 2000; 54: 229-245.

20. Araki K, Arai K, Watanabe G, Taya K. Involvement of inhibin in the regulation of follicle-stimulating hormone secretion in the young adult male Shiba goat. J Androl 2000; 21: 558-565.

21. Taya K, Watanabe G, Sasamoto S. Radioimmunoassay for progesterone, testosterone and estradiol $17 \beta$ using ${ }^{125}$ I-iodohistamine radiolligands. Jpn J Anim Reprod 1985; 31: 186-197.

22. Webb R, Gong JG, Law AS, Rushbridge SM. Control of ovarian function in cattle. J Reprod Fertil 1992; 45 (Suppl): 141-156.

23. Badinga L, Driancourt MA, Savio JD, Wolfenson D, Drost M, de La Sota RL, Thatcher WW. Endocrine and ovarian responses associates with the first-wave dominant follicle in cattle. Biol Reprod 1992; 47: 871-883.

24. SAS. Statistics, version 6.11, Cary, NC: SAS Institute Inc. 1987.

25. Kaneko H, Terada T, Taya K, Watanabe G, Sasamoto S, Hasegawa Y, Igarashi M. Ovarian follicular dynamics and concentrations of oestradiol-17 beta, progesterone, luteinizing hormone and follicle stimulating hormone during the periovulatory phase of the oestrous cycle in the cow. Reprod Fertil Dev 1991; 3: 529-535.

26. Kaneko H, Nakanishi $\mathbf{Y}$, Taya K, Kishi H, Watanabe G, Sasamoto S, Hasegawa Y. Evidence that inhibin is an important factor in the regulation of FSH secretion during the mid-luteal phase in cows. J Endocrinol 1993; 136: 35-41.

27. Medan MS, Watanabe G, Sasaki K, Nagura Y, Sakaime H, Fujita M, Sharawy S, Taya K. Effects of 
passive immunization of goats against inhibin on follicular development, hormone profile and ovulation rate. Reproduction 2003; 125: 751-757.

28. Medan MS, Watanabe G, Nagura Y, Kanazawa H, Fujita M, Taya K. Passive immunoneutralization of endogenous inhibin increases ovulation rate in miniature Shiba goats. J Reprod Dev 2004; 50: 705710.

29. Vinoles C, Meikle A, Forsberg M, Rubianes E. The effect of subluteal levels of exogenous progesterone on follicular dynamics and endocrine patterns during early luteal phase of the ewe. Theriogenology 1999; 51: 1351-1361.

30. Rubianes E, Ungerfeld R, Vinoles C, Rivero A, Adams GP. Ovarian response to gonadotropin treatment initiated relative to wave emergence in ultrasonically monitored ewes. Theriogenology 1997; 47: 1479-1488.

31. Driancourt MA, Webb R, Fry RC. Does follicular dominance occur in ewes? I Reprod Fertil 1991; 93: 63-70.

32. Duggavathi R, Bartlewski PM, Barrett DM, Gratton C, Bagu ET, Rawlings NC. Patterns of antral follicular wave dynamics and accompanying endocrine changes in cyclic and seasonally anestrous ewes treated with exogenous ovine follicle-stimulating hormone during the inter-wave interval. Biol Reprod 2004; 70: 821-827.

33. Leyva V, Buckrell BC, Walton JS. Regulation of follicular activity and ovulation in ewes by exogenous progestagen. Theriogenology 1998; 50: 395-416.

34. Flynn JD, Duffy P, Boland MP, Evans AC. Progestagen synchronisation in the absence of a corpus luteum results in the ovulation of a persistent follicle in cyclic ewe lambs. Anim Reprod Sci 2000; 62: 285-296. 